\title{
Health complaints following an air disaster: a "second disaster"
}

\section{A Page, S C Wessely}

\section{Commentary on the paper by Huizink et al (see page 657)}

$\mathrm{R}^{\mathrm{c}}$ esearch into the medium and long term health consequences of disaster has mushroomed in recent years. The majority of this research has focused on direct "victims", that is, members of the general population who have been directly exposed to disaster. Emergency workers and other occupational groups have been less studied, possibly due to the assumption that adverse health effects will be minimal for them. The study by Huizink et al in this issue ${ }^{1}$ is therefore a particularly welcome addition to the disaster literature; the authors investigate an occupational cohort who performed rescue work during, what turned out to be, one of the strangest man-made disasters of recent timesthe 1992 Amsterdam (or Bijlmermeer) Air Disaster.

Huizink et al invited a cohort of police officers and fire-fighters to participate in the study; over half the participants had done disaster related work at the time of the Amsterdam Air Disaster and were considered "exposed". Unfortunately recruitment took place eight years after the disaster, meaning that exposure assessment had to be both highly retrospective and self-reported. Despite this limitation the authors are able to convincingly show that the prevalence of somatic symptoms (including fatigue) is increased among police officers and firefighters who did disaster related work compared to those that did not. This increase in symptoms is general and not limited to specific organ systems, a finding which is congruent with studies of civilian populations exposed to disaster. ${ }^{2}$ Blood and urine tests were normal in the exposed workers, supporting the conclusion that the symptoms are likely to be medically unexplained Mental health outcomes are also increased in those who did disaster related work; for example, the odds of developing post-traumatic stress disorder (PTSD) is over two and half times higher in those police officers who had done disaster related work. Nearly al mental health outcome measures were elevated in police officers, a reminder that PTSD is only one of a number of adverse psychiatric outcomes following disaster. The risk of having poor mental health was increased more clearly in police officers than fire-fighters-possibly because there was greater power in the police officer cohort, although baseline differences in education or institutional differences cannot be discounted

The study highlights the need for future registers of the occupationally exposed to be set up as soon as possible after large incidents, although the difficulties of doing this are considerable. Disasters happen unpredictably and immediate concern is usually with the preservation of life and operational issues. A full register of those involved in the rescue and clean-up post-disaster requires rapid cooperation with occupational health departments-something that cannot be assumed in countries with, for example, a strong culture of litigation. Nevertheless, occupational registers have been set up following several high profile disasters, including $9 / 11$, the Madrid bombings, the Enschede fireworks explosion, and the Buncefield fire. The ongoing attempt to establish a 7th July London Bombings register illustrates the difficulty of getting such registers set up promptly. Occupational registers are substantial undertakings, but they are likely to be worthwhile in certain circumstanceswhen the disaster has involved considerable death and destruction or when there is likely to be litigation and/or contested causation. In the case of the Amsterdam Air Disaster it was clear that the first of these conditions was met from the outset; the second condition was also met, although this took some time to emerge.

So why should police and fire-fighters who were occupationally exposed to disaster have more mental and physical symptoms than their non-exposed colleagues so many years after the event? After all police officers and fire-fighters are trained to deal with such an eventuality, and when proper epidemiological studies are performed that compare different occupations, police officers are known to have low background rates of psychiatric disorder. ${ }^{3}$
This latter finding might surprise some people used to the endless stream of studies that involve administering stress questionnaires to police officers as part of "stress" studies, and remind us of the problems of context and bias in these kinds of studies. Indeed there is evidence from other disaster scenarios that emergency worker groups usually have better mental health outcomes than direct survivors, ${ }^{4}$ and sometimes better than the (indirectly exposed) general population. ${ }^{5}$ In the case of the Amsterdam Air Disaster, it seems that exposed police and fire crews have similar, or worse, outcomes to that which we might expect direct survivors to exhibit. Why is this? To answer this question we need to look at the social and political context of the Amsterdam Air Disaster rather than the specific traumatic experiences or pre-morbid adjustment of the emergency workers.

Yzermans and Gersons ${ }^{6}$ have neatly outlined the key events that occurred after the Amsterdam Air Crash. They point out the sequential failings of the authorities to quell rumour and misinformation following the disaster, thereby highlighting the importance of coherent governmental handling in the aftermath of a large incident. In the years that followed the disaster, the direct survivors, emergency workers, and residents of the Bijlmermeer were all exposed to numerous rumours, for example that the El-Al plane had been carrying a secret toxic cargo, that there was depleted uranium in the plane's tail, and that Mossad agents had been seen picking through the wreckage. A lack of credible information from the Dutch government meant that these conspiracy theories were allowed to take root and flourish. Added to this, maverick scientists began to publicise supposed links between mycoplasma infection, depleted uranium, and people's symptoms. Local action groups were formed to represent people who believed they had become ill due to the disaster. By 1998, more and more symptomatic victims were presenting to services and a public health crisis had developed. Ultimately a Parliamentary inquiry was set up and the level of public interest was such that it was televised on Dutch television. The final Parliamentary report in 1999 concluded that there was no evidence of any unusual toxic exposure.

The parallels with Gulf War syndrome are obvious, even down to the implied role of depleted uranium in the genesis of the illnesses. Is it possible to piece together the crucial factors that precipitated this "second" Amsterdam air disaster? Why did mental and physical symptoms attributed to the disaster 
increase rather than decrease as the years passed? Certainly risk communication strategies on the part of the Dutch government were inadequate, which meant that official communication about the disaster was reactive and sometimes contradictory. This resulted in a loss of public trust and after a certain point no official information was deemed credible. The media undoubtedly played a key role in fuelling the crisis, as Vasterman et $a l^{7}$ showed ecologically when they plotted media "scares" against the number of people reporting disaster related health problems. Unbalanced media coverage allowed inaccurate rumour to prevail, to the point that mysterious toxic poisoning became the dominant explanatory model to account for people's symptoms.

The Amsterdam Air Disaster is a salient case study of how events can unfold in the aftermath of an incident, leading to what has been termed a "second" disaster. Unfortunately there are other long running examples, Camelford in the UK and Three Mile Island in the USA being just two of the best known cases. Occupational groups may be trained to deal with the physical and emotional strain of disaster related work, but they are also members of a community and therefore vulnerable to the same socio-political influences that can impinge on the community as a whole.

Occup Environ Med 2006;63:647-648. doi: 10.1136/oem.2006.028142

\section{Authors' affiliations}

L A Page, S C Wessely, Institute of Psychiatry, King's College, London, UK

Correspondence to: Dr L A Page, Section of General Hospital Psychiatry, Room 3.14,

Weston Education Centre, Institute of Psychiatry, King's College London, 10 Cutcombe Road, London SE5 9RJ', UK; I.page@iop.kcl.ac.uk
Competing interests: none declared

\section{REFERENCES}

1 Huizink $A C$, Slottje $P$, Witteveen $A B$, et al. Long term health complaints following the Amsterdam Air Disaster in police officers and fire-fighters. Occup Environ Med 2006:63:657-62.

2 van-den-Berg B, Grievink L, Yzermans J, et al. Medically unexplained physical symptoms in the aftermath of disasters. Epidemiol Rev 2005;27:92-106.

3 Stansfeld S, Head J, Rasul F, et al. Occupation and mental health: secondary analyses of the ONS Psychiatric Morbidity Survey of Great Britain, Research Report 168. London: Health \& Safety Executive, 2003.

4 Galea S, Nandi A, Vlahov D. The epidemiology of post-traumatic stress disorder after disasters. Epidemiol Rev 2005;27:78-91.

5 Miguel-Tobal J, Vindel A, Iruarrizaga I, et al. Psychopathological repercussions of the March 11 terrorist attacks in Madrid. Psychology in Spain 2005;9:75-80.

6 Yzermans J, Gersons B. The chaotic aftermath of an airplane crash in Amsterdam: a second disaster. In: Havenaar J, Cwikel J, Bromet E, eds. Toxic turmoil. New York: Kluwer, 2002:85-101.

7 Vasterman P, Yzermans C, Dirkzwager A. The role of the media and media hypes in the aftermath of disasters. Epidemiol Rev 2005;27:107-14

\section{bmjupdates+}

bmjupdates+ is a unique and free alerting service, designed to keep you up to date with the medical literature that is truly important to your practice.

bmjupdates+ will alert you to important new research and will provide you with the best new evidence concerning important advances in health care, tailored to your medical interests and time demands.

Where does the information come from?

bmjupdates+ applies an expert critical appraisal filter to over 100 top medical journals A panel of over 2000 physicians find the few 'must read' studies for each area of clinical interest

Sign up to receive your tailored email alerts, searching access and more...

www.bmjupdates.com 